\title{
The efficiency and quality dilemma: What drives South African call centre management performance indicators?
}

\author{
Authors: \\ Diane Banks ${ }^{1}$ \\ Gert Roodt ${ }^{1}$ \\ Affiliations: \\ ${ }^{1}$ Department of Industrial \\ Psychology and People \\ Management, University of \\ Johannesburg, South Africa \\ Correspondence to: \\ Gert Roodt \\ Email: \\ groodt@uj.ac.za \\ Postal address: \\ PO Box 524, Auckland Park \\ 2006, South Africa \\ Dates: \\ Received: 07 Oct. 2010 \\ Accepted: 12 Jan. 2011 \\ Published: 29 Mar. 2011 \\ How to cite this article: \\ Banks, D., \& Roodt, G. \\ (2011). The efficiency and \\ quality dilemma: What \\ drives South African call \\ centre management \\ performance indicators? \\ SA Journal of Human \\ Resource Management/ \\ SA Tydskrif vir \\ Menslikehulpbronbestuur, \\ 9(1), Art. \#331, 17 pages. \\ doi:10.4102/sajhrm. \\ v9i1.331
}

(C) 2011. The Authors

Licensee: OpenJournals

Publishing. This work

is licensed under the

Creative Commons

Attribution License.
Orientation: Call centres have become principal channels of communication with customers. Therefore, companies attempt to reduce costs and improve the quality of their interactions with customers simultaneously. These objectives are often conflicting and call centre managers struggle to balance the efficiency and quality priorities of the business.

Research purpose: This study explored the key performance indicators that drive management practices in the South African call centre industry in the context of the dilemma between efficiency and quality.

Motivation for the study: The South African government has identified call centres as a method of creating jobs and foreign investment. Management practices affect centres' performance. Understanding these practices will help to achieve these aims.

Research design, approach and method: The researchers used a web-based questionnaire in a survey with South African call centre managers in more than 44 different organisations that represented nine industry sectors.

Main findings: This study indicated that the dilemma between efficiency and quality is prevalent in South African call centres and that efficiency key performance indicators drive management practices.

Practical/managerial implications: The inconsistencies the study reported mean that South African organisations should assess the alignment between their organisational visions, the strategic intentions of their call centres and the performance measures they use to assess their call centre managers.

Contribution/value-add: This study adds to the relatively small amount of empirical research available on the call centre industry in South Africa. It contributes to the industry's attempt to position itself favourably for local and international outsourcing opportunities.

\section{Introduction}

The strategic role of call centres is changing. It has become the primary way of delivering services and the main source of contact for customers. Companies attempt to achieve customer satisfaction by offering their customers easy access to their services and products whilst lowering their costs through a consolidated approach. This approach has its problems and managers struggle to balance the efficiency and quality imperatives of their businesses. This research focuses on these conflicting objectives and investigates the performance indicators that drive management practices in the South African call centre industry.

An array of easily accessible measures, which call centre technology offers, enables efficiency. These measures focus on call quantities and performance targets and offer data like:

- the number of calls waiting

- the proportion of calls answered

- the average call duration

- the customer waiting time.

Neely, Bourne and Kennerley (2003) suggested that there is too much measuring. Radnor and McGuire (2004) found that the role of call centre managers is administrative rather than managerial. 
Managers focus on efficiency measures rather than on managing the quality of the customer experience - the courtesy, friendliness, and enthusiasm of call centre agents (CCAs). Call centre managers have to decide on practices that will meet the companies' expectations of rationalised operations whilst ensuring employee wellbeing and customer satisfaction.

Numerous researchers have investigated the conflicting nature of these call centre objectives well (Bain \& Taylor, 2000; Batt, 1999; Houlihan, 2002; Kinnie, Hutchinson \& Purcell, 2000; Taylor \& Bain, 1999; Wallace, Eagleson \& Waldersee, 2000). These studies suggest that the two objectives - efficiency and quality - are contradictory. Dean and Rainnie (2009, p. 326) captured the discrepancy in their reference to the call centre as 'a unique and contradictory service environment'.

There is an increased interest in the South African call centre industry as a way of creating jobs and foreign investment. This has given the industry a high level of visibility. Trade and Industry Minister Rob Davies stated, at the 2009 launch of the Department of Trade and Industry investment call centre in Soweto, that 'the call centre is an apex government priority in terms of the Cabinet Plan of Action of 2007' (Department of Trade and Industry 2009a, para.2). Nimrod Zalk, deputy director-general of the Industrial Development Division, supported this. At the Business Process Outsourcing Week, held in November 2009, Zalk suggested that the government has prioritised and committed itself to the off-shoring industry (Department of Trade and Industry, 2009b).

This study contributes to the research on call centres in three ways:

- There have been relatively few empirical studies on the local call centre industry. The South African government's interest in call centres makes this industry important. Therefore, the study aimed to add to the body of research.

- In an overview of the current literature on call centres, Robinson and Morley (2007) and Russel (2008) concluded that research has concentrated on the labour processes call centres use and the experiences of CCAs. This study intended to use information from call centre managers to establish what drives call centre management practices in South Africa and how these relate to the dilemma between efficiency and quality.

- The third addresses Burgess and Connel's (2004) suggestion that most call centre literature comes from case studies. This is evident in the empirical studies on the call centre industry in South Africa. They suggested that surveys should supplement the current research. This study used a survey that elicited responses from more than 44 different businesses representing nine industry sectors. This provided a broad foundation on which to base conclusions.

Batt and Moynihan (2002, p. 18) suggested that managing front-line employees in the technology-intensive call centre environment is one of the biggest challenges facing call centre managers and that the current literature has not investigated the 'black box' that links management practices to performance outcomes fully. Therefore, this paper aims to offer more insight into South African call centre management practices and to contribute to the industry's attempt to position itself favourably for international and local outsourcing opportunities.

In exploring management practices in South African call centres, the study investigates the following core research question: 'The efficiency and quality dilemma: What drives South African call centre management performance indicators?' The specific research sub-objectives for this study are to:

- establish whether there is a strong emphasis on operational efficiency in call centres

- determine whether there is a predominant focus on the quality measures of work performance in call centres

- determine whether there is conflict between efficiency and quality measures

- establish which performance management practices call centres use.

A secondary objective of the study is to compare South African call centre management practices with Australian practices (where possible). This explains the frequent references to Robinson and Morley $(2006 ; 2007)$.

The rest of the article is in four parts. It starts with a review of the existing literature relevant to these sub-objectives. A description of the research design follows. The study then presents the results of the survey, a discussion of the theoretical and managerial implications and concludes with suggestions for further research.

\section{Literature review}

The call centre industry has grown rapidly with the development of telecommunication technology and its integration with information technology. Companies identify call centres as powerful customer channels. They also attempt to reduce costs and improve the quality of their customer interactions simultaneously.

Holman and Wood defined a call centre as:

a work environment in which the main business is mediated by computer and telephone-based technologies that enable the efficient distribution of incoming calls (or allocation of outgoing calls) to available staff, and permit customer-employee interaction simultaneously with the use of display screen equipment and the instant access to, and inputting of, information.

(cited in Holman, Wall, Clegg, Sparrow \& Howard, 2002, p. 4)

Christina Wood, the director of the 2007 Inaugural Contact Centre Global Forum, stated that over $80 \%$ of all customer interactions happen through call centres and that the industry employs six million people worldwide in this industry (Khuzwayo, 2007). 
In today's business world, call centres are an inevitable component of service delivery. One would rarely speak to anybody else but a CCA to resolve a query, to find additional information, to lodge a complaint or, in some industries, to buy a service or product.

Call centres have become multi-channelled communication centres that offer fax, email, web chat and the Internet, in addition to the traditional telephone, as communication channels for the customer. Companies choose call centres as their preferred form of interaction with customers. Call centres offer the first, and often the only, point of contact and they use call centres to differentiate their products and services from those of their competitors (Armistead, Kiely, Hole \& Prescott, 2002). Call centres have moved from occupying a relatively small niche to being a significant part of the global economy.

The call centre industry in South Africa has also experienced tremendous growth. The South African National Business Process Outsourcing (BPO) and Call Centre Report of 2008 suggested that there were about 1500 operational call centres. They employed between 150000 and 170000 CCAs nationally (Multimedia Group \& C3Africa, 2008). This report showed that most call centres were based in Gauteng (71.6\%), that there was a tendency towards smaller centres with fewer than twenty seats, and that South Africa was largely a captive environment where organisations own the centre and use it exclusively for their own purposes (65.5\%). The most significant function the centres perform is to address the queries of customers. The financial services industry used call centres the most.

Call centres are highly measured environments. Developments in the computer and telephone-based technologies have allowed call centre managers, from their desks, to track the number of calls that CCAs take within any given time, the speed with which they answer the calls, the duration of the calls, the number of abandoned calls and the time that CCAs spend off the phone. In fact, managers are able to monitor every minute that CCAs spend in the office. In addition to these quantitative measures, calls are recorded. This enables managers to listen to conversations in order to assess the CCAs' tone of voice, enthusiasm and friendliness.

The focus on monitoring performance has elicited various investigations into the effect that this practice has on CCAs and managers. Some authors defined the CCAs' work as closely monitored and controlled by technology, typically very routine and monotonous with little opportunity for personal discretion and poorly paid (Bain, Watson, Mulvey, Taylor \& Gall, 2002; Taylor \& Bain, 1999).

Others presented a more positive picture. They suggested that call centre work varied widely and that there were environments that offered CCAs some flexibility and discretion (Deery \& Kinnie, 2002; Frenkel, Tam, Korczynski \& Shire, 1998; Korczynski, 2002). Richardson and Howcroft (2006, p. 60), in their classification of call centres as 'utopian' or 'dystopian' environments supported these opposing views. Constant monitoring, excessive surveillance, de-motivated CCAs and high production targets characterise the latter. In contrast, empowered agents, who had the flexibility and knowledge to adopt a customer-focused approach, typify utopian environments.

Houlihan (2001) found that call centre managers had become preoccupied with logistics and statistics. Managers focused on predicting call peaks and used technology to manage callhandling patterns proactively:

we witness a separation of the system management and 'man' management tasks ... the call centre is taking away many of the choices managers make about how they do their job.

(Houlihan, 2011, p. 212)

Call centre managers were expected to maintain required service levels (the percentage of calls answered within a specific period) and the quality of service (the courtesy, friendliness, and enthusiasm the CCAs offer) without exceeding operational budgets (Halliden \& Monks, 2005).

To investigate further the dilemma between efficiency and quality, in which call centre managers find themselves, the study discusses the literature under the four research subobjectives mentioned above.

\section{Operational efficiency in call centres}

The integration of information and computer technologies, to optimise service delivery to customers, is central to call centres. Taylor and Bain (1999, p. 115) called this integration the 'Taylorisation of white-collar work'. This is characterised by an increase in managers' powers, highly fragmented tasks and extensive controlling and monitoring of employees. They proposed that most call centres relied heavily on technology to increase CCAs' production but stated that these technologies 'cannot secure the requisite quality performance' essential in a service environment (p. 111). Frenkel et al. (1998, p. 966) called these properties of technology 'informative control'. Robinson and Morley (2007, p. 250) suggested that the manager's role has changed from 'that of active investigator, director and overseer of work activities to that of monitor and evaluator of the worker's performance'.

The development of sophisticated electronic monitoring and the extensive use of data in managing operational efficiency resulted in the critical assessment of call centres as the ideal environment to exercise 'Panopticon' control (Foucault, 1997). Panopticon refers to a prison design that Jeremy Bentham proposed more than two hundred years ago. This design allowed the wardens to observe and control prisoners continuously without the prisoners seeing them - 'the Panopticon induces in the prisoner a state of congruence and permanent visibility that assures the automatic functioning of power' (Robinson \& Morley, 2007, p. 250). Foucault (1997) used this design as a metaphor for describing call centre practices. Fernie and Metcalf (1998, p. 9) suggested that 'the agents are constantly visible and the supervisor's power has been rendered perfect via the computer monitoring screen.' 
Authors like Bain and Taylor (2000); Barnes (2004); Richardson and Howcroft (2006); and Robinson and Morley (2007) contested this view. They suggested that the claim of complete managerial control denied the existence and importance of CCAs' resistance to control structures. In addition to this, Robinson and Morley (2007) stated that, although it was evident that centres used efficiency data to monitor performance, the managers' intentions were more than pure control.

The Global Call Centre Report (Holman, Batt \& Holtgrewe, 2007) explored 2500 call centres in 17 countries. They found that using data from call centre technology was a widespread activity. In this regard, call centres in South Africa ranked amongst those with the highest degree of call centre monitoring (Benner, Lewis \& Omar, 2007).

This study aimed to investigate the extent to which call centres in South Africa used efficiency measures. This led to the first hypothesis of the study:

Hypothesis 1: There is a high focus on efficiency in South African call centres.

\section{Quality work performance}

The wide variety of call centre technologies available focuses mainly on a common goal - to offer quality interactions that satisfy customers.

Feinberg, Ik-Suk, Hokama, De Ruyter and Keen (2000) undertook an empirical study to assess the predictors of customer satisfaction. They identified 13 critical elements in general use and assessed how they related to caller satisfaction. The data from 514 call centres showed that most of the operational measures they use calculated the efficiency of the call centre. The authors concluded that 'we make important what we can measure ... the technological developments in the call centre industry may be the driver of what we think is important in call centres' (p. 131). In their assessment of the call centre literature, Aksin, Armony and Mehrotra (2007) proposed that it was necessary for call centres to develop a better understanding of customers' quality expectations and how these relate to the qualitative and quantitative management practices call centres use.

In a competitive business environment, achieving customer satisfaction is a strategic necessity and a primary objective. In their exploratory cross-sectional study in seven call centres in the Western Cape, Hart, Chiang and Tupochere (2009) reported that most managers believe that service quality was critical to the operational success of the call centres. The 2008 Contact Center Satisfaction Index indicated that 95\% of customers who had satisfying experiences with CCAs would do business with the company again (Teodoru, 2008). The American Customer Satisfaction Index concurred and illustrated a significant link between customer satisfaction and organisational profitability (Fornell, Mithas, Morgeson \& Krishnan, 2006).
There is a broad stream of literature that suggests that service quality is an important determinant of customer satisfaction and that the level of service differentiates companies from their competitors. The type of management practice call centres use affects employees' ability to provide the required service level. This in turn affects the sustainable success of the centre (Fisher, Milner \& Chandraprakash, 2007; Little \& Dean, 2006; Moshavi \& Terborg, 2002; Sergeant \& Frenkel, 2000). This survey undertook to explore whether call centres in South Africa focus on the service quality necessary for customer satisfaction. Therefore, the second hypothesis of this study is:

Hypothesis 2: The customer and the quality of the interaction with the customer are important to South African call centre managers.

\section{The conflict between efficiency and quality}

The literature indicates that efficiency and quality are both important for ensuring customer satisfaction (Armistead et al., 2002; Feinberg et al., 2000; Frenkel et al., 1998). There is, however, a concern about balancing the management of efficiency with that of quality. Batt \& Moynihan, 2002; Hart et al., 2009; Houlihan, 2002 suggest that they are two contradictory objectives and that it is not always possible to achieve both simultaneously. The interest in the practices that call centres use to manage this conflict has resulted in various research activities.

In their study of the information technology (IT) service company, Fijitsu Services, Marr and Parry (2004) provided evidence that a focus on efficiency measures could be counter-productive to achieving customer satisfaction. In support of this, Dean and Rainnie (2009, p. 332) referred to 'the clash of operational efficiency with customer demands' and used focus groups to identify the organisational factors that affected service quality. They reported that the measures call centres used were not necessarily conducive to ensuring quality service and that CCAs favoured productivity targets because these measures were more visible, frequently used and linked to job security.

A study focusing on call centre management responsibilities in Australia found that managers preferred customer service as a key performance indicator. However, in their quest to satisfy company requirements, they paid more attention to quantitative measures (Robinson \& Morley, 2006). Richardson and Howcroft (2006, p. 78) explored the inconsistency between system objectives and outcomes and talked about 'the contradictions and tensions that exist in call centre work'. Deery and Kinnie (2002); Frenkel et al. (1998); Kinnie et al. (2000); and Taylor and Bain (1999) also highlighted the competing expectations of cost-reducing management practices with the need to make customers feel important and valued.

In addition to the evidence from the literature that supports the dilemma between efficiency and quality, call centres employ some practices that promote this conflict. 
Most big call centres have electronic information boards that display real-time data about the number of calls waiting, the proportion of calls answered and the average waiting time - call statistics they use to manage call quantities. It is very seldom that these boards display any data about the quality of responses. Benner et al. (2007) found that the boards give feedback on the quantitative performance of CCAs more often than feedback and coaching related to the quality of the interactions.

In a study of the efficiency and service quality of an Israeli call centre, Raz and Blank (2007) presented the contrast between the verbal declarations of managers about the integration of quantity and quality and its collapse in the workplace. Houlihan (2001, p. 232) proposed that 'call centres are rooted in contradictory and structural paradoxes, and confront a number of trade-offs on that basis'. In their analysis of the literature about conflicting call centre objectives, Robinson and Morley (2007, p. 255) concluded 'the efficiency imperative predominates and most call centres are run along Taylorist lines'.

The literature suggests a tension between call centres' desire for customer service and their preferred focus on operational efficiency. Despite the fact that call centres may claim to have a focus on service quality, the actual practices offer a different message. This discrepancy leads to the third hypothesis of this study:

Hypothesis 3: The Key Performance Indicators (KPIs) allocated to the role of call centre managers in South Africa focus on efficiency measures.

\section{Management practices}

The literature to date has indicated that call centres are not all managed in the same manner and much research has focused on the outcome of the different practices (Frenkel et al., 1998; Taylor \& Bain, 1999; Taylor, Mulvey, Hyman \& Bain, 2002).

Call centres tended to adopt the classic mass production model associated with assembly lines. Here functions are highly specialised, skill requirements minimal and discretion disappears in favour of repetitive tasks. Batt and Moynihan (2002, p. 16) suggested that the mass production model assumed that a job could be designed as 'turn-over proof' with workers as 'replaceable parts'. They researched the economic viability of three models of service delivery and concluded that call centres seldom used a professional service model with high quality individualised services and a focus on training and knowledge.

In a study of four call centres in Gauteng, Fisher, Miller and Thatcher (2007, p. 48) found that South African call centre management practices 'have a historic disposition towards control and Taylorism' and focused on production irrespective of the conceptual service model.

Some studies have investigated the relationship between control and empowerment. Houlihan (2002) used four British call centres to examine low discretion and high commitment in action. Discretion refers to the extent to which CCAs can make personal decisions when dealing with customers. High commitment practice suggests strategies like high discretion, job scope, job security and involvement initiatives.

This study found little evidence of an in-depth application of high commitment practices and suggested that the focus was rather on the quantity of calls and performance targets. Managers were reluctant to compromise efficiency for quality service or employee well-being. Wallace et al. (2000, p. 174) referred to the adoption of a 'sacrificial HR strategy'. Managers sacrificed employee well-being to achieve efficiency and accepted burnout and high turnover as part of the management strategy.

Frenkel et al. (1998) offered a more positive picture. They suggested an approach where work organisation was standardised but which included some elements of flexibility and discretion.

A more recent study, undertaken by D'Cruz and Noronha (2007), also reflected this positive portrayal. It focused on the experiences of CCAs who worked in a technical call centre in India. They described an environment with complex tasks that required specialised skills and offered variety, autonomy and less standardised processes. In South Africa, Hart et al. (2009) offered evidence that the seven call centres explored in the Western Cape had a tendency towards a more empowered approach.

In contrast to most studies, Houlihan $(2001,2002)$ focused on how call centre managers experienced the conflicting requirements associated with the job. She found that they did not always adopt some practices by choice. Instead, the task-focused environment prescribed them. Work processes were centrally determined within the wider context of the organisation. Managers were ultimately accountable to the business and unable to ignore the company's focus on cost efficiency. Houlihan argued that, in many instances, managers were not empowered to manage and concluded that, like CCAs, managers also faced confusing organisational demands and conflicting role requirements. Raz and Blank (2007) talked about competing directives. Robinson and Morley (2006) stated that managers focused on performance efficiency to satisfy company requirements. Based on these arguments, the study proposes a fourth hypothesis:

Hypothesis 4: Despite the focus on efficiency measures, South African call centre managers prefer qualitative Key Performance Indicators.

\section{Conclusions about the literature review}

The quandary that managers face has become more diverse and complex with the 'two boss phenomenon' - efficiency demands from the company and quality demands from the customer (Russel, 2008, p. 202). Despite the extensive growth and development of the industry, this conflict still appears to be relevant. The effect of globalisation and the growing practice of outsourcing exacerbate it. The rationale for this practice is reduced costs and this provides the impetus for efficiency-driven management practices (Russel, 2008). 
Based on the literature that supports this conflict, this study aims to explore what drives South African call centre management KPIs and how these indicators relate to the dilemma between efficiency and quality in which managers find themselves.

\section{Research design}

This study discusses the research design under the subheadings of 'research approach' and 'research method'. Where similar information was available, it drew comparisons with the Australian study of Robinson and Morley $(2006,2007)$.

\section{Research approach}

The researchers used a quantitative, cross-sectional approach to develop an outsider's perspective of the management practices at call centres in South Africa and gives accurate descriptions of them (Huysamen, 1998).

The researchers conducted a survey using a web-based questionnaire that they adapted from the Robinson and Morley $(2006,2007)$ study that assessed the management responsibilities in Australian call centres.

Statkon, a statistical consultancy associated with the University of Johannesburg, hosted the questionnaire. It collated all the responses.

The researchers did correlation data analysis to assess whether, and how strongly, variables related to each other.

\section{Research method}

Four headings present the research method:

- sample and sampling procedure

- measuring instrument

- research procedure

- data analysis.

\section{Sample and sampling procedure}

The target population for this study was call centre managers in South Africa. C3Africa Research and The Multimedia Group did a comprehensive market analysis of the local call centre industry and published the South African National BPO and Call Centre report (Multimedia Group \& C3Africa, 2008). This report used the database of their web-based information resource, the Contact Industry Hub. It contained 1342 call centres.

The researchers adopted various approaches whilst developing the sampling frame to target as many call centre managers from as many industries as possible. Andy Quinan, from C3Africa, placed the survey on the Contact Industry Hub website and advertised it in its newsletter on 10 March 2010.

The researchers extracted call centre managers from an existing client and contact list, approached potential participants at the 2010 Call Centre Conference that Knowledge Resources hosted and identified call centres from the telephone directory as well as the Internet. They approached personnel agencies, human resource departments, training companies and consultants operating in the call centre industry. Some agreed to distribute the questionnaire to their respective client bases.

Of the 180 questionnaires circulated, respondents returned 111 usable questionnaires. This is a response rate of $62 \%$. The 130 questionnaires the Robinson and Morley (2006, 2007) survey used showed a similar response rate. Some organisations have more than one call centre and the returned questionnaires represented more than 44 different South African businesses.

In terms of the 1342 call centres in the Contact Industry Hub database, the number of responses for this survey does not seem to represent the whole population. However, most call centre literature comes from case studies and focuses on a few organisations (Burgess \& Connel, 2004).

Compared to the Australian survey, on 37 large companies, the questionnaires the researchers used in this study represent more than 44 different businesses from nine industry sectors. Because most of the empirical studies on the South African call centre industry have been case studies, the number of participating organisations and the variety of industry sectors in this study is a sufficiently broad base from which to describe the management practices call centres in South Africa use.

Table 1 gives some insight into the different industry sectors represented in the sample and indicates that most of the respondents came from a financial services environment. The South African National BPO and Call Centre report (Multimedia Group \& C3Africa, 2008) supports this. It found that there were more call centres in this sector than in any other of the industries. The table also shows that most of the participating call centres have between 51 and 100 seats and there was a higher number of smaller call centres. This is consistent with the 2008 report.

In contrast, Robinson and Morley $(2006,2007)$ used large call centres with a minimum of 100 employees for their study. Participating centres managed both in-bound and outbound calls, 77\% have been operational for more than five years and $31.3 \%$ indicated an annual attrition rate of less than $5 \%$. This relatively low attrition rate was evident in both the South African National BPO and Call Centre report (Multimedia Group \& C3Africa, 2008). They showed an attrition rate of above 45\%. The Robinson and Morley $(2006,2007)$ survey showed that $33 \%$ of their participating call centres had an annual attrition rate of less than $5 \%$.

The responses further reported that most of the call centres in this sample operated seven days a week, 24 hours a day. As with the Robinson and Morley (2006) survey, the results 
TABLE 1: Demographic details of participating call centres.

\begin{tabular}{|c|c|c|}
\hline Demographic details & $N$ & $\%$ \\
\hline \multicolumn{3}{|l|}{ Industry sector } \\
\hline Financial services & 49 & 47.1 \\
\hline Telecommunications & 36 & 34.6 \\
\hline Retail or fast-moving consumer goods (FMCG) & 12 & 11.5 \\
\hline Utilities & 6 & 5.8 \\
\hline Entertainment or hospitality & 5 & 4.8 \\
\hline Travel & 4 & 3.8 \\
\hline Health & 3 & 2.9 \\
\hline IT & 2 & 1.9 \\
\hline Government & 2 & 1.9 \\
\hline Total & $119^{a}$ & - \\
\hline \multicolumn{3}{|l|}{ Number of seats } \\
\hline Less than 50 & 24 & 24.0 \\
\hline 51-100 & 31 & 31.0 \\
\hline $101-200$ & 16 & 16.0 \\
\hline $201-300$ & 10 & 10.0 \\
\hline $301-500$ & 4 & 4.0 \\
\hline More than 500 & 15 & 15.0 \\
\hline Total & $100^{b}$ & - \\
\hline \multicolumn{3}{|l|}{ Call types } \\
\hline Inbound & 23 & 23.2 \\
\hline Outbound & 8 & 8.1 \\
\hline In or outbound & 68 & 68.7 \\
\hline Total & $99^{\mathrm{b}}$ & - \\
\hline \multicolumn{3}{|l|}{ Annual attrition \% } \\
\hline Less than 5 & 30 & 31.3 \\
\hline $5-10$ & 27 & 28.1 \\
\hline $10-20$ & 28 & 29.2 \\
\hline More than 20 & 11 & 11.5 \\
\hline Total & $96^{b}$ & - \\
\hline \multicolumn{3}{|l|}{ Years operational } \\
\hline $1-5$ & 23 & 23.0 \\
\hline More than 5 & 77 & 77.0 \\
\hline Total & $100^{b}$ & - \\
\hline
\end{tabular}

TABLE 2: Characteristics of call centre managers in South Africa and Australia.

\begin{tabular}{|c|c|c|c|}
\hline \multirow[t]{2}{*}{ Characteristics } & \multicolumn{2}{|c|}{ South Africa } & \multirow{2}{*}{$\begin{array}{c}\text { Australia } \\
\%\end{array}$} \\
\hline & $N$ & $\%$ & \\
\hline \multicolumn{4}{|l|}{ Gender } \\
\hline Male & 55 & 48.0 & 48 \\
\hline Female & 56 & 52.0 & 52 \\
\hline \multicolumn{4}{|l|}{ Age (years) } \\
\hline $20-30$ & 28 & 25.0 & 16 \\
\hline $31-40$ & 48 & 43.0 & 47 \\
\hline Over 40 & 35 & 32.0 & 37 \\
\hline \multicolumn{4}{|c|}{ Time in current position (years) } \\
\hline Fewer than 1 & 12 & 11.0 & - \\
\hline $1-4$ & 46 & 42.2 & - \\
\hline More than 4 & 51 & 46.8 & - \\
\hline \multicolumn{4}{|c|}{ Previously a call centre agent } \\
\hline Yes & 72 & 64.9 & - \\
\hline No & 39 & 35.1 & - \\
\hline
\end{tabular}

$N$, number of call centre managers.

indicated that the participating call centres had several attributes. This illustrated that the findings were not limited to a particular type of centre and made the results valid and reliable.
Table 2 gives some characteristics of the respondents for this and the Australian survey. The similar results indicate an even spread between male and female call centre managers, with the majority being in the 31 to 40 age group. Most participants in the South African study have occupied their current positions as managers for more than four years and have been call centre agents before.

\section{Measuring instrument}

The study aimed to describe call centre management practices in ways similar to those of Robinson and Morley (2006). Therefore, the researchers developed a questionnaire that contained 33 questions using the 2006 study as a starting point.

Professor Clive Morley offered a copy of, and permission to adapt, their survey. The researchers were careful to remove unrelated items to ensure that all the questions addressed the hypotheses of this study. They drew on the literature to design additional questions about performance management practices. The questionnaire included closed and open-ended items. The researchers offered sufficient options to reduce possible bias and included open-ended questions to elicit additional insights to supplement the quantitative survey data.

The researchers did a pilot test of the questionnaire with four call centre managers, who had extensive experience in the industry, to ensure further validity. These managers gave feedback about the relevance of each item, the clarity of the questions, the structure of the survey and the time that it took to complete. Their insights contributed to ensuring that the questions were clear and likely to elicit accurate information to measure what the survey intended to. As in the Robinson and Morley (2006) study, the researchers considered the time constraints of the call centre managers in the design. It took about 15 minutes to complete.

In an attempt to identify the consistency of the responses and to explore the concepts from different angles, the researchers cross-referenced responses with different items. They improved the reliability of the data by using a good sample size and ensuring that respondents had the necessary experience as call centre managers to offer meaningful responses.

The questionnaire fell into five sections to orientate the respondents and to improve clarity (Babbie \& Mouton, 2001). The discussion that follows offers more information about the content of the different sections of the questionnaire.

Sections 1, 2 and 3 - The call centre manager, the organisation and the call centre: The first three sections included general information about the manager, the organisation, and the set-up of the particular call centre. This was to give a better understanding of the context in which the centre used its management practices.

Section 1 dealt with biographical details about the call centre manager. They included age, gender, time in current position 
and previous experience as a call centre agent (items 1.1 to 1.5). Section 2 explored the organisation in terms of its industry sector, its mission and vision (items 2.1 and 2.2). The third section enquired about the number of seats in the call centre, the operating hours, the type of calls it handled, the number of years that it has been operational, the annual agent turnover rate and the focus of the centre (items 3.1 to $3.8)$.

Section 4 - Performance measurement practices: This section gathered information about the call centre's performance measuring practices, like call monitoring, the use of display boards, the customer satisfaction measures it uses and the coaching activities it undertakes (items 4.1 to 4.11 ).

Section 5 - The role of call centre manager: Section 5 addressed issues about the role of the call centre manager. Respondents identified those aspects of their jobs that they enjoyed most and least (items 5.1 and 5.2). The researchers grouped these responses into target-driven activities and people-management activities. The researchers explored the KPIs firstly by asking the respondents to identify the three highest-weighted indicators that were allocated to their roles (item 5.4) and then to write their own KPIs specifying the three most important indicators (item 5.5). Respondents had to select measures that they felt determined the success of their call centres (item 5.7) and identify the first performance measure that they looked at when they had been absent from the office. The researchers excluded responses to an item that identified the single biggest constraint to executing the role of call centre manager from the study because of a technical error on the web-based questionnaire (item 5.3).

\section{Research procedure}

Robinson and Morley (2006) distributed their questionnaire via mail to two hundred call centre managers. For this survey, the researchers sent 180 respondents an emailed invitation to participate in the survey. This clarified the procedures, offered the link to the website, explained the broad aims of the study and emphasised anonymity and confidentiality. To increase the response rate, the researchers personalised invitations where possible and offered the respondents a summary of the findings in exchange for their participation. The researchers collected data over a period of two months, starting in February 2010. They sent two email reminders to encourage participation during this period.

\section{Data analysis}

The web-based questionnaire enabled the capture of all data directly into a central database that expedited the processing of the data. The researchers gave the frequency distributions of the responses and did cross tabulations to assess the relationship between variables. The frequency distributions indicated a clear preference for certain variables, with the result that there was not the required minimum number of responses in some of the cross tabulation cells to perform the Chi-Square test. As in the Robinson and Morley (2006, 2007) study, the researchers adopted a descriptive approach to present the results of the survey.

\section{Research results}

To present the results of the 111 returned questionnaires, the researchers used the research hypotheses to structure the information. Where possible, they compared the results to those from the Robinson and Morley (2006) study. The researchers used the response frequencies to the items to assess each hypothesis. They are discussed and a summary of the results concludes this section.

Hypothesis 1 - There is a high focus on efficiency in South African call centres: The researchers used a variety of items to identify which measures call centres in South Africa focused on: items 4.2, 4.4, 4.6, 4.8, and 4.10.

The Robinson and Morley $(2006,2007)$ survey reported that 91\% of call centres in Australia used call monitoring. Table 3 illustrates this high preference in South Africa as well (96\%). This table presents the frequency distributions for items that address the most important measures call centres use in monitoring calls (item 4.2) and in assessing customer satisfaction (item 4.6).

These results show that respondents identified the quality of the interactions with customers as the main aspect that call centres used in monitoring calls $(75.5 \%)$ compared to efficiency measures, like the average call handling time and the number of calls taken. To support this, the researchers identified the quality of interactions as the most important measure call centres used to assess customer satisfaction in item $4.6(65.9 \%)$. The Australian survey indicated that $58 \%$ of call centres used call monitoring, customer surveys and waiting times as measures of customer service standards.

Table 4 presents the results for item 4.8. This examined the measures managers use to evaluate the quality of service. Contrary to the results presented thus far, $48.9 \%$ of participating managers ranked compliance with business processes as the most important. The CCAs' politeness to customers $(35.6 \%)$ followed.

These two measures were also the most important aspects of the coaching activities of the call centres in item 4.10. However, it is important to note that businesses usually design their processes to ensure that customers' requests are managed effectively within the structure of the organisations. Therefore, these focus on satisfying the organisational and customers' needs. This is a possible reason for these apparently different results.

Table 5 records the results for items 4.3 and 4.4. The researchers recorded disparate results for item 4.4. This enquired about the measures call centres used on the monitoring display boards. A total of $78 \%$ of call centres in Australia and $67.7 \%$ of centres in South Africa used display boards. Only $12.3 \%$ of call centres in South Africa that used these boards displayed qualitative measures. Table 5 reports the frequencies for the four variables in this item. It suggests that display boards usually displayed information like the number of calls waiting and average waiting time, the number of available agents and the number of abandoned 
TABLE 3: Call monitoring, monitoring measures and customer satisfaction measures.

\begin{tabular}{|c|c|c|c|}
\hline Item measured & Rank importance & $N$ & $\%$ \\
\hline \multicolumn{4}{|c|}{ Item 4.1: Do you use call monitoring in your call centre? } \\
\hline Yes & - & 96 & 96.0 \\
\hline No & - & 4 & 4.0 \\
\hline \multicolumn{4}{|c|}{ Item 4.2: What is the one most important aspect to monitor? } \\
\hline Average handling time & - & 12 & 12.8 \\
\hline Quality of interaction & - & 71 & 75.5 \\
\hline Number of calls taken & - & 11 & 11.7 \\
\hline \multicolumn{4}{|c|}{ Item 4.6: Rank the items in terms of their importance in measuring customer satisfaction } \\
\hline \multirow[t]{3}{*}{ Number of abandoned calls } & 1 st & 8 & 9.8 \\
\hline & 2nd & 28 & 34.1 \\
\hline & $3 r d$ & 46 & 56.1 \\
\hline \multirow[t]{3}{*}{ Quality of interaction } & 1 st & 54 & 65.9 \\
\hline & 2nd & 18 & 22.0 \\
\hline & $3 r d$ & 10 & 12.2 \\
\hline \multirow{2}{*}{ Number of calls answered in $\mathrm{x}$ seconds } & 2nd & 36 & 43.9 \\
\hline & $3 \mathrm{rd}$ & 26 & 31.7 \\
\hline
\end{tabular}

$N$, used as means of number.

TABLE 4: Measures of service quality and aspects to coach.

\begin{tabular}{|c|c|c|c|c|c|c|c|c|c|c|}
\hline \multirow[t]{3}{*}{ Measures } & \multicolumn{10}{|c|}{ Rank importance } \\
\hline & \multicolumn{2}{|c|}{ Most important } & \multicolumn{2}{|c|}{ 2nd } & \multicolumn{2}{|c|}{$3 r d$} & \multicolumn{2}{|c|}{ 4th } & \multicolumn{2}{|c|}{ 5th } \\
\hline & $N$ & $\%$ & $N$ & $\%$ & $N$ & $\%$ & $N$ & $\%$ & $N$ & $\%$ \\
\hline \multicolumn{11}{|c|}{$\begin{array}{l}\text { Item 4.6: Rank the importance of each item in measuring service } \\
\text { quality }\end{array}$} \\
\hline Average handling time & 4 & 4.4 & 16 & 17.8 & 16 & 17.8 & 31 & 34.4 & 23 & 25.6 \\
\hline Compliance with business processes & 44 & 48.9 & 21 & 23.3 & 17 & 18.9 & 5 & 5.6 & 3 & 3.3 \\
\hline Number of calls taken & 4 & 4.4 & 6 & 6.7 & 14 & 15.6 & 31 & 34.4 & 35 & 38.9 \\
\hline Politeness towards customers & 32 & 35.6 & 32 & 35.6 & 17 & 18.9 & 8 & 8.9 & 1 & 1.1 \\
\hline Adherence to script & 6 & 6.7 & 15 & 16.7 & 26 & 28.9 & 15 & 16.7 & 28 & 31.1 \\
\hline \multicolumn{11}{|c|}{ Item 4.10: What are the three most important aspects to coach? } \\
\hline Number of calls taken & 16 & 6.6 & - & - & - & - & - & - & - & - \\
\hline Average handling time & 28 & 11.5 & - & - & - & - & - & - & - & - \\
\hline Adherence to script & 46 & 18.9 & - & - & - & - & - & - & - & - \\
\hline Politeness to customers & 77 & 31.7 & - & - & - & - & - & - & - & - \\
\hline
\end{tabular}

$N$, used as means of number.

calls. However, it is important to note that call centres use some quantitative measures, like the number of calls waiting and average waiting time, as indicators of the level of service they offer to customers. Therefore, the researchers achieved the first objective of the study.

Hypothesis 2 - The customer and the quality of the interaction with the customer are important to South African call centre managers: Table 6 presents the results for items 3.6 and 4.5. These asked call centre managers to select the most important focus of their centres and whether they measured customer satisfaction.

The results showed that $84.5 \%$ of participating call centres measured customer service. The majority of participants $(77.6 \%)$ ranked customers as the most important and statistics and agents as the least important focus of the call centres. The Robinson and Morley $(2006,2007)$ survey reported that 97\% of call centres in Australia measured customer service standards and that $38 \%$ of respondents chose 'customers mattered' as most descriptive of their call centres.
Of the responses that identified customers as the focus of the call centre, table 7 illustrates that $78.4 \%$ also indicated the quality of the interaction with customers as the most important measure in call monitoring.

The responses to item 2.2 further supported the importance of the customer. Here, most call centre managers (78\%) indicated that their organisations mentioned customer service in their vision or mission statements. The questionnaire asked respondents to quote sections from the statements that were most relevant to their call centres. Responses report the examples that follow:

- a total focus on customer needs to meet or exceed their expectations at all times

- inspiring and leading our clients and our people on a journey to deliver exceptional customer experiences

- to allow clients to focus on their core business by providing tailored and responsive customer service solutions that improve service quality and exceed client and end-user satisfaction, loyalty and expectations. 
TABLE 5: Monitoring boards.

\begin{tabular}{|c|c|c|}
\hline Results & $N$ & $\%$ \\
\hline \multicolumn{3}{|c|}{ Item 4.3: Does your call centre have call monitoring display boards visible to the agents? } \\
\hline Yes & 65 & 67.7 \\
\hline No & 31 & 32.3 \\
\hline \multicolumn{3}{|c|}{ Item 4.4: What information is displayed on these boards? } \\
\hline Number of calls waiting or average waiting time & 60 & 36.8 \\
\hline Number of available agents & 43 & 26.4 \\
\hline Qualitative performance scores & 20 & 12.3 \\
\hline Number of abandoned calls & 36 & 22.1 \\
\hline
\end{tabular}

$N$, used as means of number.

TABLE 6: The focus of the call centre.

\begin{tabular}{|c|c|c|c|c|c|c|}
\hline \multirow[t]{3}{*}{ Results } & \multicolumn{6}{|c|}{ Rank importance } \\
\hline & \multicolumn{2}{|c|}{ 1st } & \multicolumn{2}{|c|}{ 2nd } & \multicolumn{2}{|c|}{ 3rd } \\
\hline & $N$ & $\%$ & $N$ & $\%$ & $N$ & $\%$ \\
\hline \multicolumn{7}{|c|}{ Item 3.6: What is the most important focus of your call centre? } \\
\hline Statistics matter & 11 & 11.2 & 23 & 23.5 & 64 & 65.3 \\
\hline Agents matter & 11 & 11.2 & 58 & 59.2 & 29 & 29.6 \\
\hline Customers matter & 76 & 77.6 & 17 & 17.3 & 5 & 5.1 \\
\hline \multicolumn{7}{|c|}{ Item 4.5: Do you measure customer satisfaction? } \\
\hline Yes & 82 & - & 84.5 & - & - & - \\
\hline No & 15 & - & 15.5 & - & - & - \\
\hline
\end{tabular}

$N$, used as means of number.

The Robinson and Morley study $(2006,2007)$ confirmed the importance of customers. Here, $89 \%$ of respondents indicated that their companies referred to customer service in their mission statements, visions or values. The focus on more qualitative measures, as reported in items 4.2 and 4.6, further supported the suggestion that customers and the quality of the interactions with customers were important to call centre managers in South Africa. Therefore, the researchers achieved the second objective of the study.

Hypothesis 3 - The Key Performance Indicators allocated to the role of call centre manager in South Africa focus on efficiency measures: To investigate the roles of call centre managers, item 5.4 asked participants to list the three highestweighted KPIs allocated to their roles. The researchers identified four categories from the responses. These were:

- quantitative indicators, like the number of abandoned calls and service levels

- qualitative indicators, like the quality of audits and coaching activities

- financial indicators, like gross profit and achieving budgets

- indicators that focus on customer satisfaction.
Eighty participants completed this item. The results in table 8 indicate that $26.3 \%$ of respondents listed a quantitative indicator as the highest-weighted KPI allocated to the role of call centre manager. A financial indicator $(23.8 \%)$ followed.

The various combinations of KPIs further confirmed the preference for quantitatively allocated indicators. Of the $26.3 \%$ of respondents who listed a quantitative indicator as the highest-weighted KPI, 22.2\% listed the same category for the other two KPIs. This suggested that the three highestweighted KPIs allocated to the role were quantitative. Of the $16.3 \%$ of responses that indicated a qualitative indicator as having the highest weight, 33.3\% listed quantitative indicators for the other two KPIs. When respondents listed a financial indicator as having the highest weight, $22.2 \%$ of respondents offered a quantitative indicator for the other two KPIs. The Robinson and Morley (2006) survey reported similar results. Here $37 \%$ of call centre managers listed a quantitative measure as the most important KPI. Only 15\% reported a qualitative indicator.

Item 5.8 supported the focus on quantitative indicators in call centre managers' KPIs. This enquired about the first single

TABLE 7: Cross tabulation of the measures used in call monitoring and the importance of the customer in the call centre focus.

\begin{tabular}{|c|c|c|c|c|c|c|}
\hline \multirow[t]{3}{*}{ Results } & \multicolumn{6}{|c|}{ Item 4.2: Most important measure used in call monitoring } \\
\hline & \multicolumn{2}{|c|}{ Average call handling time } & \multicolumn{2}{|c|}{$\begin{array}{l}\text { Quality of interaction with } \\
\text { customer }\end{array}$} & \multicolumn{2}{|c|}{ Number of calls taken } \\
\hline & $N$ & $\%$ & $N$ & $\%$ & $N$ & $\%$ \\
\hline \multicolumn{7}{|c|}{ Item 3.6: The importance of the customer in the call centre focus } \\
\hline Most important & 9 & 12.2 & 58 & 78.4 & 7 & 9.5 \\
\hline Second most important & 3 & 18.8 & 10 & 62.5 & 3 & 18.8 \\
\hline Third most important & 0 & 0.0 & 3 & 75.0 & 1 & 25.0 \\
\hline \multicolumn{7}{|c|}{$\begin{array}{l}\text { Item 2.2: Does your organisation mention customer service in its } \\
\text { vision/mission statement? }\end{array}$} \\
\hline Yes & 81 & 78.6 & - & - & - & - \\
\hline No & 22 & 21.4 & - & - & - & - \\
\hline
\end{tabular}

$N$, used as means of number. 
TABLE 8: Highest-weighted KPIs allocated to call centre managers.

\begin{tabular}{lll}
\hline Item 5.4: Highest-weighted KPIs & $\boldsymbol{N}$ & $\mathbf{\%}$ \\
\hline Quantitative indicators & 21 & 26.3 \\
Qualitative indicators & 13 & 16.3 \\
Financial indicators & 19 & 23.8 \\
Customer satisfaction & 13 & 16.3 \\
\hline
\end{tabular}

$\mathrm{N}$, used as means of number.

TABLE 9: The first performance measure call centre managers look at if they have been out of the office.

\begin{tabular}{lll}
\hline Item 5.4: Highest-weighted KPIs & $\boldsymbol{N}$ & $\mathbf{\%}$ \\
\hline Quantitative indicators & 21 & 26.3 \\
Qualitative indicators & 13 & 16.3 \\
Financial indicators & 19 & 23.8 \\
Customer satisfaction & 13 & 16.3 \\
\hline
\end{tabular}

$N$, used as means of number.

TABLE 10: Measures reported to senior managers.

\begin{tabular}{lcc}
\hline $\begin{array}{l}\text { Item 5.6: Three most important measures } \\
\text { reported to senior managers }\end{array}$ & $\boldsymbol{N}$ & $\mathbf{\%}$ \\
\hline Number of calls answered within X seconds & 40 & 17.2 \\
Average handling time (call duration and wrap-up) & 11 & 4.7 \\
Service quality offered by agent & 61 & 26.2 \\
Number of calls taken & 31 & 13.3 \\
Abandoned calls & 23 & 9.9 \\
Customer satisfaction rating & 45 & 19.3 \\
Number of coaching sessions & 22 & 9.4 \\
\hline
\end{tabular}

performance measure that managers checked when they had been out of the office. Table 9 presents the results for this item and suggests that $27.8 \%$ of managers looked at the number of calls answered within a specific period. The agents' service quality $(22.2 \%)$ followed. It is interesting to note the low customer satisfaction rating (13.3\%). A possible reason for this could be that service levels are part of the customer satisfaction measure. This quantitative measure gives call centre managers some insight into how long customers wait for service. Therefore, it indicates the level of service that call centres offer.

In the interviews they conducted with six call centre managers, Robinson and Morley (2006) reported similar results and suggested that most managers first looked at measures related to the productivity of the call centre and considered these more important to report to senior managers. In contrast, table 10 shows that the three most important measures reported to senior managers in South African call centres were the quality of service the agents offer $(26.2 \%)$, the customer satisfaction rating $(19.3 \%)$, and the level of service (17.2\%). Therefore, the researchers have achieved the third research objective of this study.

Hypothesis 4 - Despite the focus on efficiency measures, South African call centre managers prefer qualitative Key Performance Indicators: Item 5.5 asked the respondents what the three most important KPIs would be if they had to write their own indicators. The researchers identified the same four categories as for item 5.4 and reported the results in table 11. These suggest that most respondents offered qualitative $(25.7 \%)$ and customer satisfaction indicators $(23 \%)$ as their preferred KPIs. It also yields similar results to the Robinson and Morley (2006) study, where 37\% of respondents listed an indicator related to customer satisfaction and service measures.

Item 5.1 highlighted the South African managers' preference for qualitative indicators. This asked what the managers enjoyed most in their roles. The results in table 12 suggest that $60.9 \%$ of managers preferred the people management activities, like developing and empowering people, interfacing with customers and staff and working with a group to achieve the required outcomes. In contrast to this, $11.5 \%$ of respondents preferred activities, like monitoring and analysing call centre statistics for projections and scheduling in order to meet monthly targets.

Table 13 shows that, of the $26.3 \%$ of respondents who listed a quantitative indicator as the highest-weighted KPI, 60\% indicated that they enjoyed people-management activities most. Managers also identified the quality of service agents offered $(26.7 \%)$ and the customer satisfaction rating (25.4\%) as measures that determine the success of call centres for item 5.7. Robinson and Morley (2006) similarly reported that 58\% of managers ranked measures related to customer service as most important for their call centres.

Both studies showed a very clear preference for measures associated with the quality of service and customer satisfaction as opposed to those measures that address the quantitative aspects of call centres. The frequencies in the South African study for quantitative measures, like the number of calls agents took $(2.5 \%)$, the number of abandoned calls $(2.5 \%)$, and the average call handling time $(3.4 \%)$ were all relatively low.

The results shown in table 14 are interesting. This is a cross tabulation of items 5.4 and 4.2. Item 5.4 listed the highestweighted KPIs allocated to managers and item 4.2 identified the one most important aspect to measure in monitoring calls. The frequency distribution suggests a strong preference for the qualitative measure in monitoring calls, irrespective of the type of KPI allocated to managers. Therefore, the researchers have achieved the fourth objective of the study.

The results suggest that customers were the focus of call centres in both South Africa and Australia and that the quality of the interaction with customers was important to call centre managers. This interaction with customers was highly emphasised in the call monitoring activities, as was assessing the levels of customer satisfaction. Response frequencies for quantitative measures, like the number of calls, the average call handling time, the number of calls within a specific period and the number of abandoned calls were relatively low.

Despite this preference for qualitative measures, the information offered to CCAs on monitoring display boards 
TABLE 11: Preferred KPIs for call centre managers in South Africa and Australia.

\begin{tabular}{lcc}
\hline Preferred KPIs & $\boldsymbol{N}$ & $\mathbf{\%}$ \\
\hline Item 5.5: South African preferred KPIs & & \\
Quantitative indicators & 11 & 14.9 \\
Qualitative indicators & 19 & 25.7 \\
Financial indicators & 12 & 16.2 \\
Customer satisfaction & 17 & 23.0 \\
Australian preferred KPIs & & \\
Level of service & - & 20.0 \\
Sales & - & 17.0 \\
Cost & - & 7.0 \\
Customer satisfaction or service & - & 37.0 \\
\hline
\end{tabular}

$N$, used as means of number.

TABLE 12: Functions and measures that determine success that the managers enjoyed most.

\begin{tabular}{lcc}
\hline Functions and measures & $\boldsymbol{N}$ & $\mathbf{\%}$ \\
\hline $\begin{array}{l}\text { Item 5.1: What you enjoy most in your role as call } \\
\text { centre manager? }\end{array}$ & 10 & 11.5 \\
Target-driven activities & 53 & 60.9 \\
People-management activities & 24 & 27.6 \\
Other & & \\
Item 5.7: Three measures that determine the success & & \\
of the call centre & 29 & 12.3 \\
Staff turnover & 18 & 7.6 \\
Number of calls answered within X seconds & 6 & 2.5 \\
Number of abandoned calls & 8 & 3.4 \\
Average handling time (call duration and wrap-up) & 6 & 2.5 \\
Number of calls taken by agent & 60 & 25.4 \\
Customer satisfaction rating & 12 & 5.1 \\
Agent occupancy rate & 63 & 26.7 \\
Service quality offered by agent & 34 & 14.4 \\
\hline Effectiveness of technology &
\end{tabular}

$N$, used as means of number.

focused mostly on quantitative measures like the number of calls waiting and average waiting time, the number of available agents, and the number of abandoned calls. In addition, the highest-weighted KPIs allocated to call centre managers in both countries appeared to be quantitative.

Both studies suggested that the number of calls CCAs answered within a specific period was the first performance measure that managers checked when they had been out of the office. In contrast to this, managers reported that their personal choice was qualitative KPIs and indicators that focused on customer satisfaction and that they enjoyed the people-management activities associated with their jobs most. Further, managers identified qualitative measures, like the quality of service agents offered and the customer satisfaction rating, as critical for the success of call centres.
The care the researchers took in designing the questionnaire, the pre-testing and because the sample represented many different types of call centres from various industry sectors, supported the reliability of these results. The responses were therefore not restricted to a particular type of call centre, its size, industry or function.

\section{Discussion}

Call centres have become the primary source of contact for customers for companies attempting to reduce costs and improve the quality of their customer interactions simultaneously. Research has proposed that these objectives - quality and efficiency - are contradictory and that managers struggle to balance these company imperatives (Batt, 1999; Bain \& Taylor, 2000; Wallace et al., 2000; Houlihan, 2002; Kinnie et al., 2000; Raz \& Blank, 2007; Taylor \& Bain, 1999).

The purpose of this research was to investigate the management practices call centres in South African use in ways similar to the Robinson and Morley (2006) study in the context of the dilemma between efficiency and quality.

In South Africa, the call centre industry has been identified as an important source of creating jobs and foreign investment. Despite this, there have been relatively few empirical studies on the local industry and, as Burgess and Connel (2004) suggested, most of the literature comes from case studies.

This study conducted a survey with call centre managers from more than 44 different organisations, representing nine industry sectors. It aimed to supplement the comparatively small base of empirical literature and to contribute to the South African call centre industry's attempt to position itself favourably for both local and international outsourcing opportunities.

The researchers explored the core research question - 'The efficiency and quality dilemma: What drives South African call centre management performance indicators?' using these sub-objectives:

- to establish whether there is a high focus on operational efficiency in call centres

- to determine if there is a predominant focus on the quality measures of work performance in call centres

- to determine whether there is conflict between efficiency and quality measures

- to establish which performance management practices call centres use.

TABLE 13: Cross tabulation of the aspects managers enjoyed most and the highest-weighted allocated KPIs.

\begin{tabular}{|c|c|c|c|c|c|c|}
\hline \multirow[t]{3}{*}{ Item 5.4 Highest-weighted allocated KPIs } & \multicolumn{6}{|c|}{ Item 5.1: Aspects most enjoyed in role } \\
\hline & \multicolumn{2}{|c|}{ Target driven activities } & \multicolumn{2}{|c|}{ People management activities } & \multicolumn{2}{|c|}{ Other } \\
\hline & $N$ & $\%$ & $N$ & $\%$ & $N$ & $\%$ \\
\hline Quantitative indicators & 5 & 25.0 & 12 & 60.0 & 3 & 15.0 \\
\hline Qualitative indicators & 0 & 0.0 & 10 & 76.9 & 3 & 23.1 \\
\hline Financial indicators & 1 & 5.6 & 11 & 61.1 & 6 & 33.3 \\
\hline Customer satisfaction & 1 & 7.7 & 8 & 61.5 & 4 & 30.8 \\
\hline
\end{tabular}

$N$, used as means of number. 
TABLE 14: Cross tabulation of the highest-weighted allocated KPIs and the most important measures in monitoring calls.

\begin{tabular}{|c|c|c|c|c|c|c|}
\hline \multirow[t]{3}{*}{ Item 5.4: Highest- weighted allocated KPIs } & \multicolumn{6}{|c|}{ Item 4.2: Most important measure to monitor } \\
\hline & \multicolumn{2}{|c|}{ Average call handling time } & \multicolumn{2}{|c|}{$\begin{array}{l}\text { Quality of interaction with } \\
\text { customer }\end{array}$} & \multicolumn{2}{|c|}{ Number of calls taker } \\
\hline & $N$ & $\%$ & $N$ & $\%$ & $N$ & $\%$ \\
\hline Qualitative indicators & 1 & 7.7 & 9 & 69.2 & 3 & 23.1 \\
\hline Financial indicators & 4 & 21.1 & 14 & 73.7 & 1 & 5.3 \\
\hline Customer satisfaction & 1 & 7.7 & 11 & 84.6 & 1 & 7.7 \\
\hline
\end{tabular}

$N$, used as means of number.

A secondary objective of the study was to compare South African call centre management practices with Australian practices (where possible). This explains the frequent references to Robinson and Morley $(2006 ; 2007)$.

This section begins with a discussion of the first two objectives under the combined heading of operational efficiency and the focus on quality in call centres. It also offers findings that challenge the focus on quality interactions with customers.

A discussion of the efficiency and quality conflict follows. This explores the key performance indicators that drive management practices. It makes general observations about the conflict between efficiency and quality in the industry.

It explores and locates its premises in the literature and practices that the call centre industry uses.

Where applicable, the researchers compare it to the Robinson and Morley (2006) study. It suggests implications for managers and highlights the limitations of the survey.

The discussion concludes with suggestions for future research.

\section{Summary of the findings}

\section{Operational efficiency and the focus on quality in the call centre}

The literature suggests that the integration of information and communication technologies, and that sophisticated real-time data enables managers to measure almost every aspect of the centre, (Jack, Bedics \& McCary, 2006) is what defines call centres.

The widespread use of technology in management has been the topic of many studies in the last decade and call centres have been accused of providing the ideal environment for the exercise of 'Panoptican' control (Fernie \& Metcalf, 1998). Although various authors dispute this, there is evidence that measuring productivity and reporting on statistics were still the prevalent focus (Houlihan, 2001; Neely et al., 2003). Despite the rapid development that has occurred in this industry, Taylor and Bain (2005) concluded that the rationale for call centres remained chiefly about containing costs and that other areas, like improving customer service, were less important.
In contrast, Hart et al. (2009) researched seven call centres in Cape Town and found that managers favoured measures that focus on customers' experiences rather than those that focus only on agent productivity. Robinson and Morley's 2006 Australian study confirms this preference. They reported that call centre managers regarded customer service as their main responsibility.

The results of this survey agree with the findings of these two studies and suggest that customers are the focal point of most of the participating centres. Managers indicated that call monitoring activities adopt qualitative measures when assessing agents' interactions with customers and when determining the level of customer satisfaction.

Respondents concur with the Robinson and Morley (2006) study. They also recorded a preference for qualitative KPIs and that they enjoyed the people-management activities associated with their jobs most. Both these studies identify qualitative measures, like the quality of the service agents offer and the customer satisfaction rating, as critical features necessary for the success of call centres.

These findings therefore do not support the first hypothesis of this study: that call centres emphasise efficiency measures. They rather support the premise that customers and the quality of the interactions are important to call centre managers in South Africa.

\section{Findings that challenge the focus on quality interactions}

However, other practices in Australian and South African centres challenge the prevalence of quality customer interactions. Although participating managers indicated low preferences for quantitative measures, these studies reported that the first measure managers checked when they had been out of the office was the number of calls taken within a specific period.

This shows the importance that managers attach to this productivity measure and contradicts their stated focus on qualitative measures.

The technology call centres use makes efficiency measures easily accessible. They offer a real-time glimpse of call centre productivity and they do contribute to the quality of service the centres offer. 
As suggested by Robinson and Morley (2007) and Marr and Parry (2004), the emphasis that call centre managers in this survey placed on the number of calls answered within a specific period seems to indicate that this measure is used as a proxy for quality and customer satisfaction. If most calls have been answered within the expected time and there are not many calls waiting, managers could assume that customers are satisfied with the level of service call centres offer. However, the service level measure simply shows whether customers had been kept waiting and offers no information about how their queries had been resolved. This ultimately creates the customer experience. Participating managers in Australia and South Africa reported that the quality of the customers' experience with CCAs mainly drives the success of call centres. The reassurance that managers in both countries derive from this measure is therefore misguided. Therefore, they should not use it as the first measurement of customer satisfaction.

A further inconsistency was the information that display boards in South African call centres offer the most. This is the number of calls waiting, the number of available CCAs and the number of abandoned calls. As suggested by Taylor and Bain (1999, p. 109), these types of measures encourage CCAs to develop an 'assembly-line in the head' and create pressure to focus on call duration so that they are available to take the next call.

Display boards are generally visible to all CCAs and offer constant reminders of the importance of the information they display. The current use of these boards in South African call centres presents conflicting messages to CCAs about what is really important in call centres. It illustrates Taylor and Bain's concept of an assembly line and is incongruent with the suggested focus on qualitative measures.

Further, Dean and Rainnie's (2009) proposal, that CCAs favour productivity targets because these measures are more visible, raises the question about which of the demands, customer satisfaction or availability, CCAs prefer in South African call centres.

Although there was evidence to support the hypothesis that customers and the quality of interactions are important to call centre managers in South Africa, these inconsistencies indicated that some call centre management practices are incongruent with this hypothesis.

\section{The conflict between efficiency and quality in management}

The findings of this study indicate that managers believe that call centres in South Africa do not emphasise efficiency and that the quality of interactions and customer satisfaction take precedence in this industry. Most participating call centre managers reported that their organisations' vision and mission statements cited the importance of customer service. This reinforces the significance of customers in the Robinson and Morley (2006) survey.
However, the KPIs of call centre managers do not corroborate this. KPIs are specific performance measures that are aligned to the success factors of the organisation and offer employees direction about what is critical and what they should focus on.

Achieving these KPIs is essential for organisational success and its sustainability (De Waal, 2002). The results of this survey indicate that, despite the importance that mission statements give to customer service, quantitative and financial measures that focus on the production efficiency of call centres were the highest-weighted performance indicators allocated to call centre managers. These findings support the third hypothesis that the KPIs allocated to call centre managers in South Africa focus on efficiency.

Robinson and Morley (2006) also report this tendency. A total of $37 \%$ of participating Australian managers listed a quantitative measure as their highest-ranked formal KPI and identified achieving financial budgets as a key aspect of managers' responsibilities. These results indicate a conflict between the intended strategic focus of organisations in South Africa and Australia and the performance measures that determine the roles of call centre managers. Despite the reported findings, that these call centres focus on customer satisfaction, the efficiency KPIs allocated to managers determines the strategic focus of management activities.

Kaplan and Norton (1992, p. 71) coined the well used phrase that 'what you measure is what you get' and suggested that organisational measures strongly influence the behaviour of employees. The participating managers' choice of a quantitative measure as the most important indication of the state of the call centre when they had been out of the office testifies to the accuracy of this statement. Although managers suggested that call centres focused on qualitative measures in most of the monitoring activities, it appears that, as Kaplan and Norton (1992) suggest, the nature of the measures allocated to them does in fact affect managers' behaviour.

Another inconsistency emerged in the differences between the allocated KPIs and the managers' preferred KPIs. When given the opportunity to list their own KPIs, managers in this and the Robinson and Morley (2006) study identified qualitative and customer satisfaction indicators as most important. Houlihan (2002) suggested that managers are not necessarily empowered to make decisions about the approaches that they adopt when managing their call centres. This argument appears to be relevant to call centres in South Africa and Australia and supports the hypothesis that call centre managers in South Africa prefer qualitative KPIs. Although managers attempt to focus on the quality of customer interactions, efficiency measures ultimately determine their success.

\section{The conflict between efficiency and quality in the industry}

The dilemma between quality and quantity seems to be evident in the prevailing call centre literature and 
in technological developments. Although the literature highlights the importance of quality in call centres, there is more empirical information on efficiency and the effect of technology than on the qualitative assessment practices in the industry.

Software vendors continually release tools that are more sophisticated to measure and report real-time productivity data automatically on each call that call centres handle. In contrast to this, qualitative measures are not as easily and readily available. Typically, these measures are not automated. They require human intervention from quality assessors who randomly select calls that they assess against predetermined performance standards.

This is labour- and time-intensive. It requires assessors with advanced skills that add to the cost per call. They can assess only a small fraction of calls in a period and this contributes to expensive interventions. Feinberg et al. (2000) suggested that technologies made some things easy to measure and this leads to automatic reporting. This argument, as well as the apparent industry focus on efficiency, supports the hypothesis that the ways of assessing call centre managers focus on quantitative aspects.

\section{Implications for managers}

In this study, there seem to be inconsistencies between the visions of organisations, the emphasis that KPIs place on quantitative performance indicators, the measures that managers consider important and some management practices that centres use. The efficiency-driven KPIs do not empower call centre managers to realise the importance their companies seem to place on quality customer experiences. Therefore, it is necessary for organisations in South Africa to assess alignments between their visions, the strategic focus of their call centres and the performance measures that determine the roles of call centre managers.

The information that display boards in South African call centres display and the managers' use of quantitative measures to establish the effectiveness of call centres contradict the intended focus on quality and present CCAs with conflicting messages. Therefore, it is essential for call centre managers to ensure that their management activities promote quality and that their display boards present the primary objectives of their call centres.

However, organisations should be cautious about how they introduce qualitative measures as performance indicators in call centres. Bain et al. (2002, p. 183) wrote about the application of numerical means of measurement' and discussed using a list of measures against which to assess the quality of interactions.

This assessment produced a score as the outcome and attached targets to it. The result was to quantify the quality that promoted the culture of achieving targets. However, quality should rather identify the performance criteria that lead to satisfied customers. Therefore, the number of quality assessments and what scores managers attain are the least important things. Rather, assessments should offer indications of how call centres satisfy customers' needs.

\section{Limitations of the study}

This study set out to investigate what determines the performance indicators of call centre managers in South Africa. The results showed a focus on quantitative and financial measures. In contrast, managers reported preferences for qualitative measures and indicated that their centres used a customer-focused approach.

The contradictions this study reported could indicate possible bias from the participating managers. Managers might have indicated what they felt the practices should be instead of reporting what actually happened in their call centres.

The researchers could have explored this possibility in interviews, as the Robinson and Morley (2006) study did.

In the light of the results, questions about how managers implemented the suggested quality approach and how they extracted the quality metrics could have added to the insights derived from this study. Robinson and Morley (2007) also reported the possibility of bias in their study of managers' views on call centres in Australia. They suggested that the managers' perspective, whether biased or not, contributed to other points of view the literature presented.

This is also the standpoint of this study.

The researchers regarded the sample size for this study as acceptable and the results offered some insight into the practices 44 different organisations used. However, the clear preference for certain options meant that the researchers did not get the required minimum number of responses for some of the cross tabulation cells. This meant that the researchers could not perform a Chi-Square test effectively.

A larger sample would have allowed better analyses of the relationships between the different variables.

\section{Future research}

This study suggested a possible lack of alignment between the performance measures for call centre managers and organisations' mission statements. The researchers suggest that future research explores the position of call centres within their organisations to identify what call centres are supposed to achieve.

The researchers also suggest that future research investigates the argument that Houlihan (2002) presents, which is that managers are not necessarily empowered to make decisions about the approaches that they use in their management of call centres.

In the light of the South African government's interest in developing the business process outsourcing industry sector, 
an investigation into the management practices employed within outsourced call centres could yield valuable information.

Holman et al. (2007) stated that the ownership status of call centres affected the management practices they use. Cost is usually an important consideration in the decision to outsource certain functions. Contracts also often put the host under pressure to increase production and reduce costs.

The nature of these agreements requires operational transparency. This could mean adopting a mass production approach to create an environment that is easily measureable. The question for future research is, therefore, the extent to which the management practices the outsourced call centres use differ from those the hosted call centres adopt.

There is relatively little scientific research available on the management practices that South African call centres use. The tremendous growth and the huge investment companies make in this industry necessitate further studies to expand the extent and depth of empirical theory on this topic.

\section{Conclusion}

This study conducted a survey amongst South African call centre managers in more than 44 different organisations representing nine industry sectors. The aim was to explore the management practices call centres South in Africa use given the dilemma between quality and quantity the literature proposes.

The results of this study show that:

- the visions of organisations promote quality customer experiences

- managers prefer qualitative measures for most of their call monitoring activities

- managers believe that customers are the focus of call centres.

In contrast, the measures that direct the management practices of call centre managers demand a focus on cost and production efficiency. These measures reinforce the focus on efficiency that earlier literature reported.

The similarity in results between the Australian study and this survey suggests that call centre managers in both countries experience the same kinds of challenges. It supports the view that the extensive use of technology limits the variation in management practices that call centres can use (Russel, 2008; Taylor et al., 2002). The results also imply that call centre managers in South Africa are not necessarily empowered to decide on appropriate management practices and that conflicting organisational demands regulate them.

This study proposes that the dilemma between quality and quantity, as discussed in the literature, is prevalent in South African call centres and that quantitative KPIs drive the management practices that call centres use. It also substantiates Russel's (2008, p. 213) argument that call centres 'preserve significant features of the past'.

\section{References}

Aksin, Z., Armony, M., \& Mehrotra, V. (2007). The modern call center: A multidisciplinary perspective on operations management research. Production and Operations Management, 16(6), 665-688. doi:10.1111/j.1937-5956.2007. tb00288.x

Armistead, C., Kiely, J., Hole, L., \& Prescott, J. (2002). An exploration of managerial issues in call centres. Managing Service Quality, 12(4), 246-256. doi:10.1108/09604520210434857

Babbie, E., \& Mouton, J. (2001). The practice of social research. Oxford University Press.

Bain, P., \& Taylor, P. (2000). Entrapped by the 'electronic panopticon'? Worker resistance in the call centre. New Technology, Work and Employment, 15(1), 2-18. doi:10.1111/1468-005X.00061

Bain, P., Watson, A., Mulvey, G., Taylor, P., \& Gall, G. (2002). Taylorism, targets and the pursuit of quantity and quality by call centre management. New Technology, Work and Employment, 17(3), 170-185. doi:10.1111/1468-005X.00103

Barnes, A. (2004). Diaries, dunnies and discipline: resistance and accommodation to monitoring in call centres. Labour and Industry, 14(3), 127-137.

Batt, R. (1999). Work organization, technology and performance in customer service and sales. Industrial \& Labor Relations Review, 52(4), 539-564. doi:10.2307/2525063

Batt, R., \& Moynihan, L. (2002). The validity of alternative call centre production models. Human Resource Management Journal, 12(4), 14-34. doi:10.1111/j.1748-8583.2002.tb00075.x

Benner, C., Lewis, C., \& Omar, R. (2007). The South African call centre industry: A study of strategy, human resource practices and performance. Retrieved November 22 of strategy, human resource practices and performance. Retrieved November 22,
2009 , from http://link.wits.ac.za/papers/South\%20Africa\%20GCC\%20Report.pdf

Burgess, J., \& Connel, J. (2004). Emerging developments in call centre research. Labour \& Industry, 14(3), 1-13.

D'Cruz, P., \& Noronha, E. (2007). Technical call centres: Beyond "electronic sweatshops" and "assembly lines in the head." Global Business Review, 8(1), 5367. doi:10.1177/097215090600800104

Dean, A.M., \& Rainnie, A. (2009). Frontline employees views on organizational factors that affect the delivery of service quality in call centres. Journal of Services Marketing, 23 (5), 326-337. doi:10.1108/08876040910973431

Deery, S., \& Kinnie, N. (2002). Call centres and beyond: a thematic evaluation. Human Resource Management Journal, 12(4), 3-13. doi:10.1111/j.1748-8583.2002. tb00074.x

Department of Trade and Industry (2009a). Launch of Department of Trade and Industry investment call centre at Soweto. Retrieved March 17, 2010, from http:// www.info.gov.za/speeches/2009/09101909051001.htm

Department of Trade and Industry (2009b). South Africa's Business Process Outsourcing (BPO) sector reaching greater heights. Retrieved March 17, 2010, from http://www.info.gov.za/speeches/2009/09113010351001.htm

De Waal, A.A. (2002). The human element in performance management systems. Quest for balance. New York: John Wiley \& Sons, Inc.

Feinberg, R.A., Ik-Suk, K., Hokama, L., De Ruyter, K., \& Keen, C. (2000). Operational determinants of caller satisfaction in the call center. International Journal of Service Industry Management, 11(2), 131-138. doi:10.1108/09564230010323633

Fernie, S., \& Metcalf, D. (1998). (Not) hanging on the telephone: payment system in the new sweatshops. Centrepiece, 3, 7-11.

Fisher, J., Milner, K., \& Chandraprakash, A. (2007). Organisational climate, job tension and job satisfaction in a South African call centre case study. Ergonomics SA, 19(2), 22-30.

Fisher, J., Miller, K., \& Thatcher, A. (2007). Performance monitoring, supervisory support, and job characteristics and their impact on employee well-being amongst four samples of call centre agents in South Africa. In Lecture notes in computer Science, 4566, 48-56. Retrieved January 20, 2010, from SpringerLink database. doi:10.1007/978-3-540-73333-1_7

Fornell, C., Mithas, S., Morgeson, F., \& Krishnan, M.S. (2006). Customer satisfaction and stock prices: High returns, low risk. Journal of Marketing, $70(1), 3-14$ doi:10.1509/jmkg.2006.70.1.3

Foucault, M. (1997). Discipline and punish: the birth of the prison. Retrieved July 17, 2010, from http://www.esubjects.com/curric/general/world history/unit three/ pdf

Frenkel, S.J., Tam, M., Korczynski, M., \& Shire, K. (1998). Beyond bureaucracy? Work organization in call centres. The International Journal of Human resource Management, 9(6), 957-979. doi:10.1080/095851998340694

Hart, M.L., Chiang, Y.-A.A., \& Tupochere, M. (2009). Balancing agent performance and customer service in contact centres. Journal of Contemporary Management, 6 151-169.

Halliden, B., \& Monks, K. (2005). Employee-centred management in a call centre. Personnel Review, 34(3), 370-385. doi:10.1108/00483480510591480

Holman, D., Batt, R., \& Holtgrewe, U. (2007). The global call centre report: International perspectives on management and employment. Retrieved January 26, 2010, from http://www.ilr.cornell.edu/globalcallcenter/upload/GCC-Intl-Rept-US-Version.pdf

Holman, D., Wall, T.D., Clegg, C.W., Sparrrow, P., \& Howard, A. (2002). The new workplace. A guide to the human impact of modern working practices. West Sussex: John Wiley \& Sons, Ltd.

Houlihan, M. (2001). Managing to manage? Stories from the call centre. Journal of European Industrial Training, 25(2/3/4), 208-220.

Houlihan, M. (2002). Tension and variations in call centre management strategies. Human Resource Management Journal, 12(4), 67-85. doi:10.1111/j.1748-8583.2002.tb00078.x 
Huysamen, G.K. (1998). Methodology for the social and behavioural sciences. South Africa: International Thomson Publishing.

Jack, E.P., Bedics, T.A., \& McCary, C.E. (2006). Operational challenges in the call center industry: a case study and resource-based framework. Managing Service Quality, 16(5), 477-500. doi:10.1108/09604520610686142

Kaplan, R.S., \& Norton, D.P. (1992). The balanced scorecard - measures that drive performance. Harvard Business Review, 70(1), 71-79.

Khuzwayo, W. (2007, April 29). SA call centres take on the world. Business Report Retrieved March 10, 2010, from http://www.busrep.co.za/index.php?fSectionld $=561 \&$ fArticleld $=3803048$

Kinnie, N., Hutchinson, S., \& Purcell, J. (2000). 'Fun and surveillance': the paradox of high commitment management in call centres. International Journal of Human Resource Management, 11(5), 967-985. doi:10.1080/095851900422375

Korczynski, M. (2002). Human resource management in service work. Hampshire: Palgrave.

Little, M.M., \& Dean, A.M. (2006). Links between service climate, employee commitment and employees' service quality capability. Managing Service Quality, 16(5), 460-476. doi:10.1108/09604520610686133

Marr, B., \& Parry, S. (2004). Performance management in call centers: lessons, pitfalls and achievements in Fujitsu Services. Measuring Business Excellence, 8(4), 55-62. doi:10.1108/13683040410569415

Moshavi, D., \& Terborg, J.R. (2002). The job satisfaction and performance of contingent and regular customer service representatives. A human capital perspective. International Journal of Service Industry Management, 13(4), 333347. doi:10.1108/09564230210445069

Multimedia Group \& C3Africa (2008). South African National BPO \& Call Centre Report. Johannesburg: Multimedia Group.

Neely, A., Bourne, M., \& Kennerley, M. (2003). Dysfunctional performance through dysfunctional measures. Cost Management, 17(5), 41-45.

Radnor, Z., \& McGuire, M. (2004). Performance management in the public sector: fact or fiction? International Journal of Productivity and Performance Management 53(3), 245-260. doi:10.1108/17410400410523783
Raz, A.E., \& Blank, E. (2007). Ambiguous professionalism: managing efficiency and service quality in an Israeli call centre. New Technology, Work and Employment, 22(1), 83-96. doi:10.1111/j.1468-005X.2007.00185.x

Richardson, H.J., \& Howcroft, D. (2006). The contradictions of CRM - A critical lens on call centres. Information and Organization, 16, 56-81. doi:10.1016/j. infoandorg.2005.10.001, doi:10.1016/j.infoandorg.2005.10.002

Robinson, G., \& Morley, C. (2006). Call centre management: responsibilities and performance. International Journal of Service Industry Management, 17(3), 284300. doi:10.1108/09564230610667122

Robinson, G., \& Morley, C. (2007). Running the electronic sweatshop: Call centre managers' views on call centres. Journal of Management and Organization, 13, 249-263. doi:10.5172/jmo.2007.13.3.249

Russel, B. (2008). Call centres: A decade of research. International Journal of Management Reviews, 10(3), 195-219. doi:10.1111/j.1468-2370.2008.00241.x

Sergeant, A., \& Frenkel, S. (2000). When do customer contact employees satisfy customers? Journal of Service Research, 3(1), 18-34. doi:10.1177/109467050031002

Taylor, P., \& Bain, P. (1999). 'An assembly line in the head': work and employee relations in the call centre. Industrial Relations Journal, 30(2), 101-117. doi:10.1111/14682338.00113

Taylor, P., \& Bain, P. (2005). 'India calling to the far away towns': the call centre labour process and globalization. Work, Employment and Society, 19(2), 261-282. doi:10.1177/0950017005053170

Taylor, P., Mulvey, G., Hyman, J., \& Bain, P. (2002). Work organisation, control and the experience of work in call centres. Work, Employment and Society, 16(1), 133150. doi:10.1177/09500170222119281

Teodoru, S. (2008). Contact Center Satisfaction Index 2008. Retrieved March 31 2010, from http://www.retailsolutionsonline.com/article.mvc/Customer-ContactImpacts-The-Bottom-Line-0003

Wallace, C.M., Eagleson, G., \& Waldersee, R. (2000). The sacrificial HR strategy in call centers. International Journal of Service Industry Management, 11(2), 174-180. doi:10.1108/09564230010323741 